\title{
PATOLOGIA DAS COMUNICAÇões COM O ANTRO DE HIGHMORE
}

Helena Maria Aranha Pinto Dias

Maria Antonieta Mano Lopes

Maria Clarisse Schneider

Neiva Andrade de Freitas Valle

Olga Elisabethe Lara Gomes

Walda Maria Domingues Matte

Alunas da $2^{\text {a }}$ série da FOPA-1970
Orientador: Hardy Ebling

Professor Titular de Patologia Geral

e Bucodental do Departamento 2

\section{SINOPSE}

Revisão bibliográfica e observa* ção em dois casos do tecido epitelial que recobre o Seio Maxilar. Em conclusão, tem-se que o Segundo Pré-molar Superior é o dente que ocasiona o maior número de comunicação do Antro de Highmore com a Cavidade Oral.

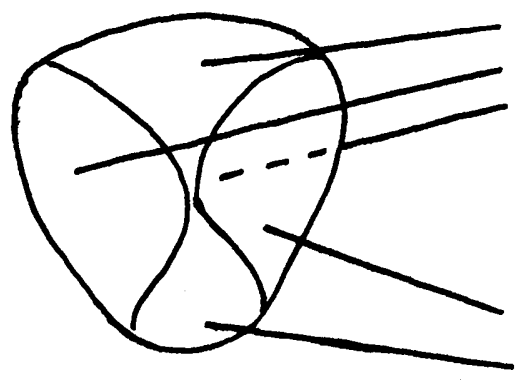

\section{CONSIDERAÇÕES ANATÔMICAS}

o seio maxilar ou antro de highmore é descrito como uma cavidade de forma piramidal, apresentando as seguintes paredes (2):

a - parede orbitária

b - - parede ântero-externa

c - base da pirâmide que está em relação com as fossas nasais e que apresenta um orifício «ostium maxilar» pelo qual comunica-se com a cavidade nasal.

d - parede póstero-externa

e - assoalho ou parede inferior

R. Fac. Odont. P.A. 
Com respeito às relações que existem entre os ápices dentário e a cavidade sinusal, se interpõe quase sempre uma capa de tecido ósseo de maior ou menor espessura entre os ápices e a cavidade do seio.

A espessura do assoalho sinusal decresce da frente para trás juntando-se, portanto, a parte mais débil na zona posterior.

o prolongamento alveolar é escavado em direção às raízes dentárias e é formado pelo intenso processo de reabsorção do tecido esponjoso que fica acima dos ápices radiculares. Esta depressão às vêzes se aprofunda entre as raizes de dois dentes vizinhos ou entre as raízes de um mesmo dente, limitando uma área de osso delgado bloqueada pelas raízes e sujeita a ser destacada na extração. O segmento alveolar é septado por cristas ósseas ou pela saliência das raízes dentais que por mais que se projetem no seio, raramente ficam em contato direto com a mucosa. Em alguns casos as raízes estão cobertas sòmente pela mucosa que forra a cavidade e pelo pericemento. Na maioria dos casos, porém, as raízes estão cobertas por uma delicada camada de osso.

\section{CONSIDERAÇOES HISTOLOGGICAS}

Interiormente, a cavidade está revestida por uma mucosa chamada membrana sinusal e que, através do orifício do seio maxilar «ostium maxilar» se continua com a mucosa que reveste as fossas nasais.

Sua superfície livre se acha re- coberta por uma camada de células epiteliais provida de cílios vibráteis que se movimentam em direção ao conduto de comunicação com a fossa nasal.

O seio é forrado por um epitélio pseudo estratificado cilíndrico rico em células caliciformes, as quais secretam um muco que umedece a superfície da mucosa do seio.

o córion ou lâmina própria funde-se ao periósteo do osso subjacente.

A mucosa se deixa descolar fàcilmente da parede óssea em condições normais em todos os seus prolongamentos. A mucosa do seio às vêzes forma pregas que chegam a dividir a cavidade do seio em compartimentos.

\section{CONSIDERAÇOES CLTNICAS Conseqüências das Comunicações}

A maioria das doenças dos seios maxilares é representada por processos inflamatórios da mucosa de origem infecciosa. Segundo Kronfeld, $80 \%$ de tôdas as doenças do seio maxilar, a infecção ganha acesso através do óstium e provém do nariz. Os restantes $20 \%$ são de origem dentária e a infecção se propaga através do assoalho do Antro de Highmore.

A participação nos processos inflamatórios de origem dentária depende, principalmente do tamanho do seio e das relações que mantém com os dentes. A delicada lâmina de osso e mucoperiósteo que constitui o assoalho do seio é fàcilmente destruída e o pús, bem como o

R. Fac. Odont. P.A.

12: $45-50, \quad 1970$ 
tecido de granulação, oriundos da lesāo dentária espalham-se na cavidade sinusal.

A infecção pulpar em dentes cujos ápices radiculares estão próximos do assoalho do seio maxilar, pode causar a infecção do mesmo. Assim, a prevenção de origem dentária é possível à custa de prevenção ou eliminação da infecção pulpar.

Qualquer operação no canal radicular das zonas dos pré-molares e molares superiores, deverá ser feita com cuidados especiais a fim de impedir a infecção do seio.

o dentista deve sempre lembrarse que a moléstia do seio maxilar pode produzir dores dentárias reflexas.

Os nervos alveolares que transitam na parede do seio podem ser envolvidos numa inflamação que afeta a mucosa ocasionando dor semelhante à dor pulpar, embora envolva no caso, um grupo de dentes.
Após a perda de molar ou prémolar o alvéolo vazio é, algumas vêzes, preenchido pelo seio maxilar. Sempre existe o risco de abrir o mesmo durante uma extração de dente adjacente a tal expansão. Se um molar permanece isolado no maxilar durante muito tempo após a perda dos dentes vizinhos, ou mesmo em desdentados, podem-se registrar expansões do seio maxilar para baixo, mesial e distal, devido ao desaparecimento da quase totalidade do tecido ósseo esponjoso da apófise alveolar e o seio maxilar se acha separado da mucosa oral só pela cortical alveolar. Isto ocasiona sérios problemas para a prótese.

A expansão dos seios em indivíduos idosos não deve ser considerada como processo de crescimento, mas sim como conseqüência da progressiva atrofia dos ossos por desuso.

QUADRO DAS RELAĢ̃é DENTO-SINUSAL (6) *

\begin{tabular}{l|c|c|c|c}
\hline & CANINO & $1^{\circ}$ PMOLAR & $2^{\circ}$ PMOLAR & MOLAR \\
\hline ZUCKERKANDL & $14 \%$ & $50 \%$ & $12 \%$ & $23 \%$ \\
\hline MUSTIAN & $29 \%$ & $26 \%$ & $31 \%$ & $14 \%$ \\
\hline GALEA & $35 \%$ & $31 \%$ & $25 \%$ & $9 \%$ \\
\hline $\begin{array}{l}\text { CASTILHO } \\
\text { GUZMAN }\end{array}$ & $0 \%$ & $2,4 \%$ & $48,78 \%$ & $\begin{array}{r}43,9 \% \\
4,8 \%\end{array}$ \\
\hline MEDIA & $19,5 \%$ & $27,4 \%$ & $29,2 \%$ & $\begin{array}{r}23,6 \% \\
\hline\end{array}$
\end{tabular}

* Os dađos acima apresentados aparecem na referência bibliográfica no 4 . As médias foram por nós obtidas a partir dêles, e que nos permitiu concluir que o $2 \circ$ Pré Molar é o que apresenta maior freqüência nas relações dento-sinusais.

P. Fac. Odont. P.A. 


\section{SYNOPSIS}

A bibliografic review of the opening between Maxillary sinus and the oral cavity including anatomics, histology and clinicals aspects.
Agradecemos ao Prof. Hardy Ebling a valiosa colaboração e ao Prof. Leopoldo Marques Louro o estímulo, sem os quais não seria possivel a elaboração dêste.

\section{REFERENCIAS BIBLIOGRÁFICAS}

1 - APRILE \& FIGUN. Anatomia odontológica. 3.ed. Buenos Aires, Atheneu, 1960, 732p. p. 508-11.

2 - BARROS, Henrique F. de. Alguns aspectos anatomo-radiográficos das relações alvéolo dentárias com o antro de Highmore. Revista Brasileira de Odontologia, Rio de Janeiro, 18: 27 mar.-abr., 1960.

3 - Camargo, G. A. Comunicações buco-sinusais. Rio de Janeiro, 1957. 63p. Tese.

4 - CASTILlO, Juan \& GUZMAN, N. T. Estudo anátomo radiográfico do seio maxilar em adulto. Revista Odont. de Concepción, Chile, 12 (2: 61. Oct.-Dec. 1967.

5 - CASTRo, Osvaldo de. Penetracão de corpos estranhos no seio maxilar. Revista APCD, São Paulo, 21 (4): 163, jul.-ago., 1967.

6 - GOMEZ, Mattaldi Recaredo A. Radiologia odontológica. Buenos Aires, Mundi, 1968 . 319p. p. 192-94.

7 - HAM, Arthur Worth. Histologia. 3.ed. Rio de Janeiro, Guanabara Koogan, 1967, 965p. p. 153-59.

8 - KRONFELD, Rudolf. Histopatologia dos dentes. 3.ed. Rio de Janeiro, Científica, 1955,550 p. p. 485 .

9 - McCALL, J. O. \& WALD, S. S. Roentgenologia - Clínica dentária. Rio de Janeiro, Atheneu, 1959. 511p. p. 436-40.

10 - ORBAN, Balint. Histologia e embriologia oral. Rio de Janeiro, Atheneu, 1955 . 446p. p. 419-27.

11 - PETERSON, E.E. Roentgenologia interpretation of anatomic lines of the maxillary of sinus. The Journal of the American Dental Association, Chicago, 53: 167, aug. 1956.

12 - SICCHER, H. \& TANDLER, J. Anatomia para dentistas. 2.ed. Madrid, Labor. 1930 , 419p. p.220-24.

R. Fac. Odont. P.A. 


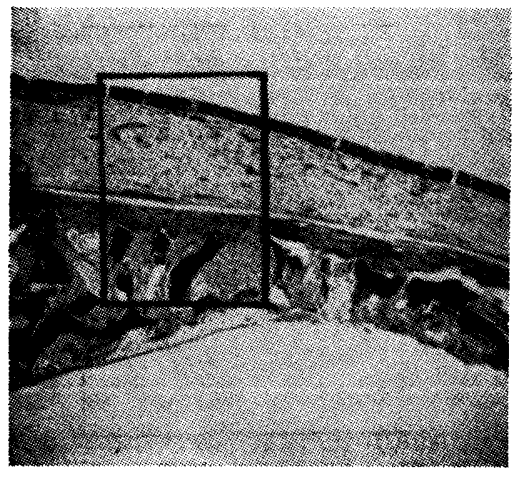

Fig. 1

Hiperemia na mucosa, arquitetura óssea alterada.
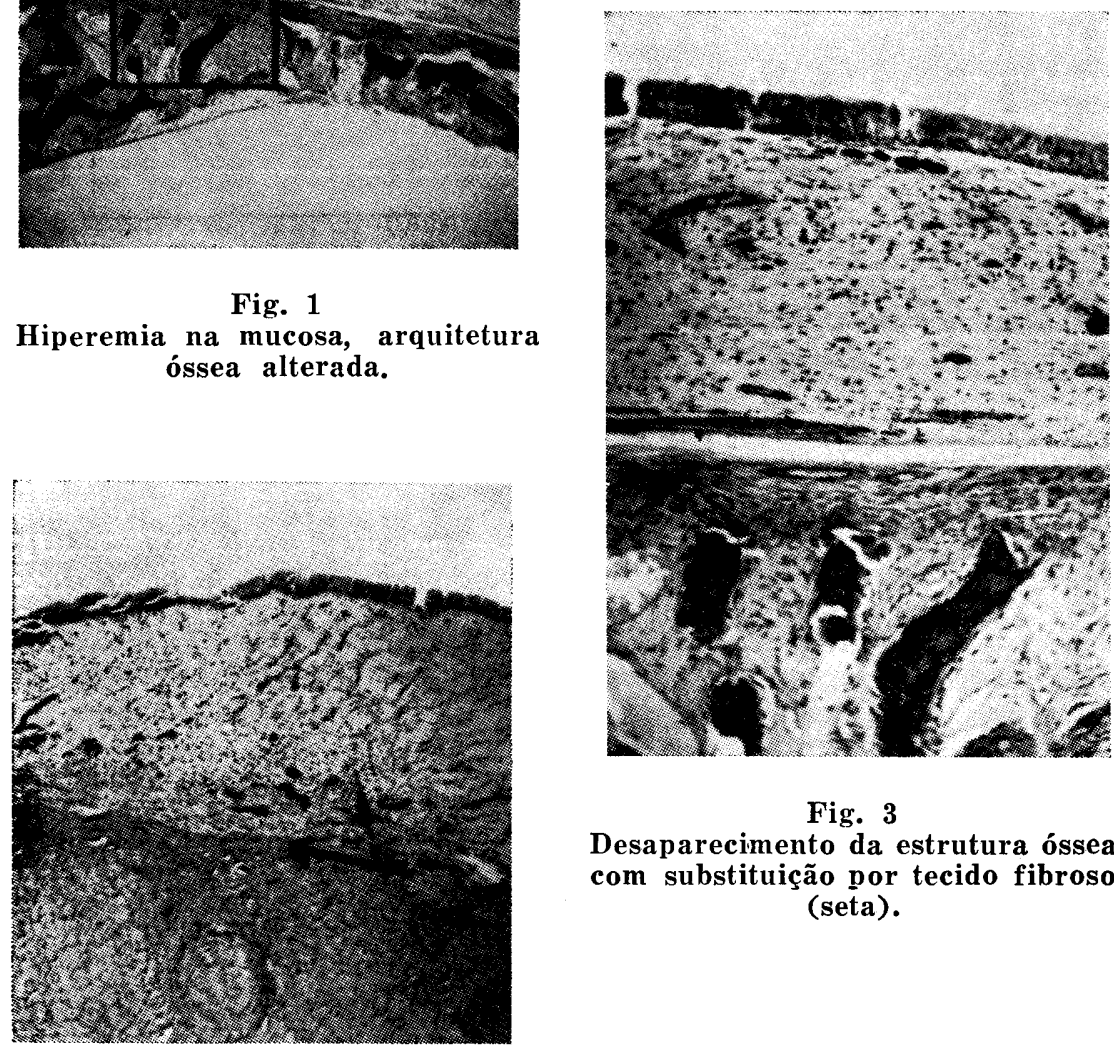

Fig. 3

Desaparecimento da estrutura óssea com substituição por tecido fibroso (seta).

Fig. 2

Maior aumento da zona assinalada na fig. 1.

R. Fac. Odont. P.A. 


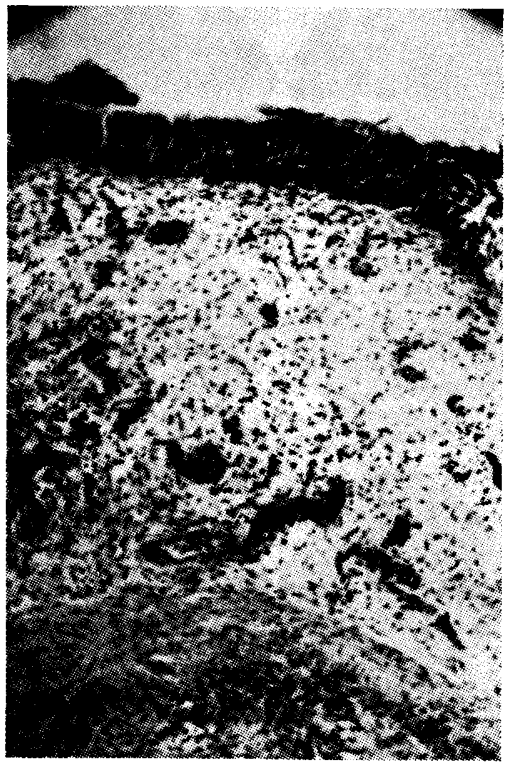

Fig. 4

Intensa hiperemia e infiltrado lin. foplasmocitário .

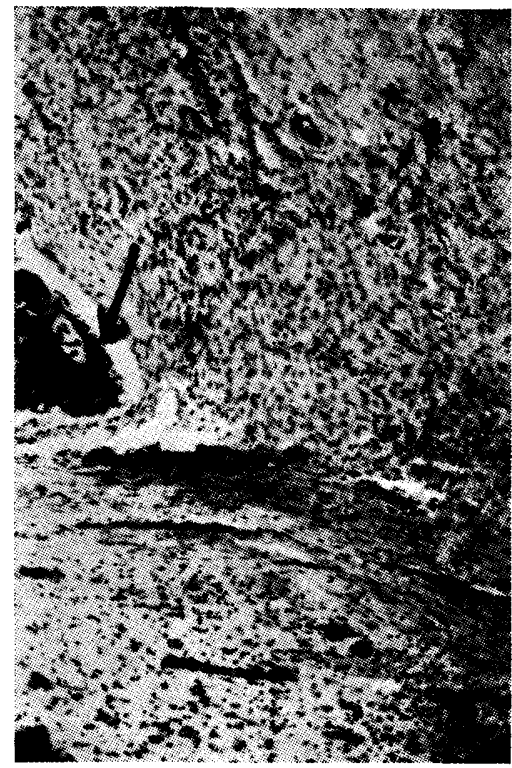

Fig. 5

Zona de comunicação entre mucosa sinusal e mucosa bucal, extremida. de do osso reabsorvido indicado pela seta.

R. Fac. Odont. P.A. 